\title{
EXPLORATION INTO MENTAL SPACES: WHERE DO LINGUISTIC EXPRESSIONS COME FROM?*
}

\author{
AYAKO OMORI \\ Osaka University
}

\begin{abstract}
This paper is an attempt to clarify the mental basis of linguistic expressions in terms of the notion of mental spaces. In this paper, I define mental spaces as constructs which the speaker has in his mind at the time of the utterance as the basis of the linguistic expression, and propose a new mental-space model which consists of three mental spaces: space $\mathrm{R}$ (speaker's reality relating to the subject of the expression), space $S$ (the subject of the expression), and space I (speaker's interpretation of space $S$ on the basis of space R). Specifically, expressions of indirect speech, metaphor, and irony are analyzed in terms of the new mental-space model.
\end{abstract}

1. INTRODUCTION. The purpose of this paper is to explore the speaker's mental construction at the time of the utterance. This study is concerned with what idea the speaker is based on when he utters something.

Focusing on the mental constructions associated with linguistic expressions, Fauconnier 1985 presents the notion of mental spaces. $\mathrm{He}$ defines mental spaces as constructs built up according to guidelines provided by linguistic expressions. The present study on mental spaces, on the other hand, involves the speaker's mental basis of the expression at the time of the utterance. Section 2 gives a new definition on mental spaces, proposes a new mental-space model, and analyzes expressions of indirect speech in terms of that new model. Section 3 and Section 4 analyze expressions of metaphor and irony respectively in terms of the same new model. Section 5 is a conclusion of the present study.

2. INDIRECT SPEECH. Indirect speech is a description of the meaning

* This paper is a revised and extended version of a paper read at the fifth annual meeting of the English Linguistic Society of Japan held at Nagoya University in November 1987. I am very grateful to Yoshimitsu Narita, Seisaku Kawakami, George D. Bedell, Minoru Nakau, Yukio Otsu, Masaaki Yamanashi, and Yukio Hirose for valuable comments and encouragement. 
of the original utterance or thought which the speaker (i.e. the reporter) has understood from his own point of view. In this section, I will consider the mental construction of the speaker involving indirect speech in terms of the notion of mental spaces.

2.1. FAUCONNIER 1985. Fauconnier's 1985 formulation of the notion of mental spaces is as follows:

I introduce the notion of mental spaces, constructs distinct from linguistic structures but built up in any discourse according to guidelines provided by the linguistic expressions. In the model, mental spaces will be represented as structured, incrementable sets-that is, sets with elements $(a, b, c, \ldots)$ and relations holding between them $\left(R_{1} a b, R_{2} a, R_{3} c b f, \ldots\right) \ldots$

(Fauconnier 1985: 16) Fundamentally, his model consists of two mental spaces: space $\mathrm{R}$ and space $M$. Space R represents speaker's reality, and space $M^{1}$ is a space established by a space-builder. In 1, for example,

(1) Len believes that the girl with blue eyes has green eyes. the space-builder Len believes sets up space M. Here, it is not in some absolute sense that we speak of Len's belief; what space M represents is the speaker's view of Len's belief (possibly different from what Len actually believes).

The expression in 1 has a noncontradictory reading such as 2 and a contradictory reading such as 3 :

(2) Lisa has blue eyes, but Len believes that she has green eyes.

(3) Len believes that Lisa has blue eyes and has green eyes.

The case in which 1 is interpreted as 2 can be explained by the mentalspace model depicted in Figure 1. The noun phrase the girl with blue eyes in 1 points to the element $a$ in space R; $a$ has a counterpart $b$ in space M. By Identification Principle (p. 3 and p. 22), the reference can shift from the trigger $a$ to the target $b$; whereby 1 indicates that ' $b$ has green eyes' holds in $\mathrm{M}$.

The case in which 1 is interpreted as 3, on the other hand, corresponds

${ }^{1}$ Fauconnier 1985 does not state clearly what the name $M$ stands for. He first uses the name $M$ on p. 16 as follows:

Expressions like " $R a_{1} a_{2} \ldots a_{n}$ holds in mental space $M$ " will be taken to mean that $a_{l}, a_{2}, \ldots, a_{n}$ are elements of $M$ and that the relation $R$ holds of $\left(a_{l}, a_{2}, \ldots\right.$, $a_{n}$ ). 


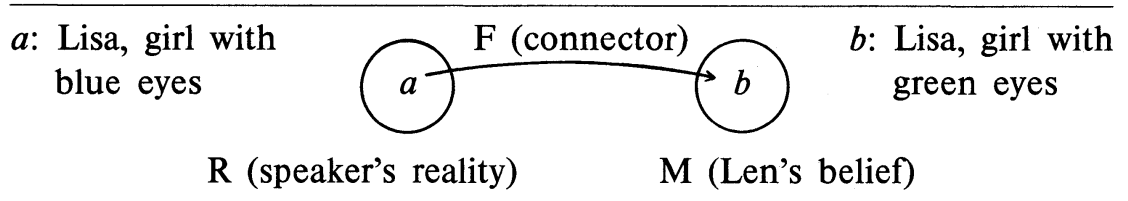

Figure 1

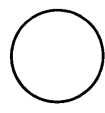

$\mathrm{R}$

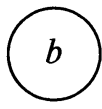

M $b$ : Lisa, who has blue eyes and has green eyes

Figure 2

to Figure 2. The element $b$, which has no counterpart in space $\mathrm{R}$, has both 'blue eyes' and 'green eyes'.

2.2. THE PROBLEMS. Fauconnier's theory is based on the idea that linguistic expressions do not refer directly to objects in the external world but point to elements in mental spaces and that the elements, in turn, refer to the external objects. I have no objection to this. There are, however, at least two problems with his model. First, his model does not explain why the speaker of 1 has produced the reported clause whose content is contradictory to the reality when he intends the 'noncontradictory' meaning. In other words, his model does not explain what the speaker of 1 means by the girl with blue eyes has green eyes.

Second, the reported propositions of 4 and 5, for instance, do not hold in any space in his model.

(4) Lucy claims that Jack called again at six. (Presupposition: 'Jack called before six')

(Context: The speaker and hearer know that Jack called before six, but Lucy doesn't; all she actually claimed was that Jack called at six, without the presupposition that he called before.)

(Fauconnier 1985: 106)

(5) According to George, Lucy is no longer beautiful.

(Presupposition: 'Lucy used to be beautiful')

(Context: All George said was that Lucy was not beautiful; he didn't know her in the past and has no idea what she looked like.)

(Fauconnier 1985: 106) 
As Fauconnier says, the presuppositions hold in space $\mathrm{R}$ but not in space M. The reported propositions ('Jack called again at six' and 'Lucy is no longer beautiful'), however, hold neither in space $\mathrm{R}$ nor in space M. In the case of 4 , the content of space $M$ is Lucy's claim that Jack called at six, without the presupposition that he called before. The content of space $\mathrm{R}$ is the speaker's knowledge that Jack called before six; the speaker does not know whether Jack really called at six as Lucy claims. In 5, the content of space M is George's assertion that Lucy is not beautiful, without the presupposition that she used to be beautiful. The content of space $\mathrm{R}$ is the speaker's idea that Lucy used to be beautiful; the speaker does not know what she looks like now.

2.3. THE RSI-MODEL. Those problems arise from the fact that Fauconnier does not pay attention to what the speaker has in his mind when he produces linguistic expressions (in the cases above, expressions of indirect speech). In order to solve the problems, I define mental spaces differently from Fauconnier:

(6) Mental spaces are constructs which the speaker has in his mind at the time of the utterance as the basis of the linguistic expression.

The distinction between Fauconnier's definition and mine is as follows: Fauconnier defines mental spaces as constructs established by linguistic expressions; whereas I define them as the mental basis of linguistic expressions. This definition follows from my idea about the relationship between a linguistic expression and the speaker's cognition at the time of the utterance. The idea is that the linguistic expression does not precede the speaker's cognition but reflects it, i.e., that the linguistic expression results from the speaker's cognition at the time of the utterance. In his mind, the speaker has what he intends to speak about, namely, a matter which he gives attention to. And he speaks about what he has judged about the matter. On the basis of this idea, I introduce a mental-space model that represents the speaker's mental construction at the time of the utterance. I call the mental-space model the RSI-model. The RSImodel consists of the following three mental spaces: space $R$, space $S$, and space I. Their definitions are given in 7:

(7) a. Space $R$ is a space that represents the speaker's mental reality relating to the content of space $S$. The content of space $\mathrm{R}$ functions as the criterion for the interpretation of the content of space $\mathrm{S}$ in space I. (The name space $R$ is 
from the initial letter of reality.)

b. Space $\mathrm{S}$ is a space that represents what the speaker intends to speak about, namely, the subject (or theme) of the expression by the speaker. (The name space $S$ is from the initial letter of subject.)

c. Space I is a space in which the speaker interprets the content of space $S$ on the basis of the content of space $R$ and forms a judgment. The judgment is reflected in the linguistic expression. (The name space $I$ is from the initial letter of interpretation.)

In fact, the speaker's mental reality can be characterized as the system of knowledge (consisting of numerous pieces of knowledge and beliefs) which the speaker has established through perceiving and cognizing the external world. When the speaker utters something, however, he uses only his reality relating to the subject (or theme) of the expression, and it is represented as the content of space $R$. Thus the content of space $R$, the speaker's reality relating to the subject of the expression, can be characterized as a piece of knowledge which the speaker has extracted from his system of knowledge. The content of space $S$, the subject of the expression, can also be characterized as a piece of knowledge which the speaker has extracted from his system of knowledge.

The mental construction of the speaker of 4 can be represented by the RSI-model as shown in Figure 3. Both the proposition $P_{1}$ and the proposition $\mathrm{P}_{2}$ (the content of Lucy's claim) have been extracted from the speaker's system of knowledge. ${ }^{2}$ In this case, $\mathrm{P}_{2}$ has come to be the content of space $S$ because $P_{2}$ is what the speaker intends to speak about. And $P_{1}$ has come to be the content of space $R$ because $P_{1}$ is the speaker's mental reality relating to the content of space $\mathrm{S}$. In space $\mathrm{I}$, the speaker interprets $\mathrm{P}_{2}$ on the basis of $\mathrm{P}_{1}$. Consequently, he forms a judgment that $P_{2}$ occurred after $P_{1}$, i.e., that Jack called again at six. That judgment represented as $\mathrm{J}$ is realized linguistically as the reported clause in 4.

Similarly, the mental construction of the speaker of 5 can be represented by the RSI-model as shown in Table. 1. The speaker interprets

2 The speaker's system of knowledge includes not only what he knows (or believes) to be a fact but also what he has been told or read, though the former and the latter are distinguished in his system of knowledge. 


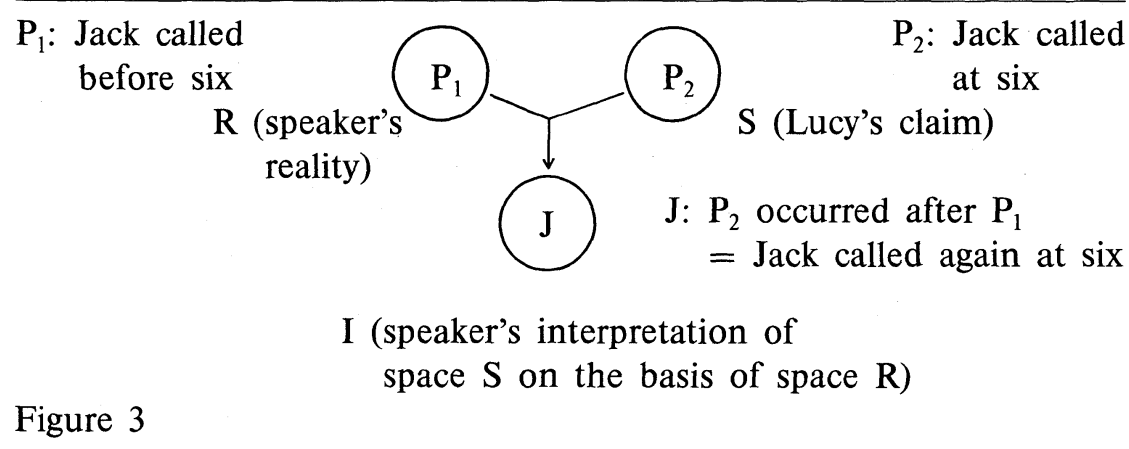

Table 1

\begin{tabular}{l|l}
\hline $\begin{array}{l}\text { space } \mathrm{R} \\
\text { (speaker's reality) }\end{array}$ & $\mathrm{P}_{1}$ : Lucy used to be beautiful \\
\hline $\begin{array}{l}\text { space } \mathrm{S} \\
\text { (George's assertion) }\end{array}$ & $\mathrm{P}_{2}$ : Lucy is not beautiful \\
\hline $\begin{array}{l}\text { space I (speaker's } \\
\text { interpretation of space S) }\end{array}$ & $\mathrm{J}$ : Lucy is no longer beautiful \\
\hline
\end{tabular}

$\mathrm{P}_{2}$ on the basis of $\mathrm{P}_{1}$ and forms a judgment $\mathrm{J}$ ('Lucy is no longer beautiful') in space I. 5 is a linguistic realization of $\mathrm{J}$.

2.4. SENSE AND REFERENCE. As we have already seen in 2.1., Fauconnier's theory clarifies the complex process of reference of noun phrases like the girl with blue eyes in 1 with 'noncontradictory' meaning, which is repeated here as 8 :

(8) Len believes that the girl with blue eyes has green eyes.

(Context: The speaker knows that Lisa has blue eyes, but Len mistakenly believes that she has green eyes.)

As I have pointed above, however, his theory does not clarify what the speaker of 8 means by the inconsistent proposition the girl with blue eyes has green eyes. In order to clarify it, we have to consider the sense of the noun phrase and that of the reported clause including it. The mental construction of the speaker of 8 can be represented by the RSI-model as shown in Table 2. The sense of the noun phrase the girl with blue eyes is shown in the notion of the girl with blue eyes originally represented as $l$ in space $\mathrm{R}$. This notion has a counterpart $l^{\prime}$ in space $\mathrm{S}$, which has a characteristic 'having green eyes'. In space I, the speaker interprets the 
Table 2

\begin{tabular}{l|l}
\hline space $\mathrm{R}$ & $l:$ Lisa, girl with blue eyes \\
\hline $\begin{array}{l}\text { space } \mathrm{S} \\
\text { (Len's belief) }\end{array}$ & $l$ : Lisa, girl with green eyes \\
\hline space I & $\begin{array}{l}\mathrm{J}: \text { the characteristic that Lisa does not really } \\
\text { have is given to her in space } \mathrm{S} \\
=\text { the girl with blue eyes has green eyes }\end{array}$ \\
\hline
\end{tabular}

content of space $\mathrm{S}$ on the basis of space $\mathrm{R}$ and judges that the characteristic which Lisa does not really have is given to her in space $\mathrm{S}$. The judgment $\mathbf{J}$ is reflected in the sense of the reported clause the girl with blue eyes has green eyes, which is inconsistent with the speaker's reality. The inconsistency in the sense of the reported clause is the reflection of the inconsistency cognized in space $\mathrm{I}$, not in space $\mathrm{S}^{3}$

2.5. REPRESENTATION IN INDIRECT SPEECH. In some cases, the representation of an individual in indirect speech differs from that of the original utterance or thought. For example:

(9) John said that he had seen the woman who lives at 219 Main Street. (McCawley 1970: 174)

(Context: What John actually said was that he had seen Mary Wilson. The speaker knows that Mary Wilson lives at 219 Main Street.)

The mental construction of the speaker of 9 can be represented by the RSI-model as shown in Table 3. In space I, the speaker interprets the content of space $\mathrm{S}$ and judges that because the individual represented as Mary Wilson in space $\mathrm{S}$ is the woman who lives at 219 Main Street, the content of John's assertion can be re-expressed as follows: he had seen the woman who lives at 219 Main Street. The judgment is reflected in the wording of the indirect speech in 9.

${ }^{3}$ If the inconsistency belonged to space $S$, the sentence 8 would have 'contradictory' meaning such as 3 , not 'noncontradictory' meaning such as 2 . 
Table 3

\begin{tabular}{l|l}
\hline space R & $\begin{array}{l}m: \text { Mary Wilson, woman who lives at 219 } \\
\text { Main Street }\end{array}$ \\
\hline $\begin{array}{l}\text { space S } \\
\text { (John's assertion) }\end{array}$ & $m^{\prime}:$ Mary Wilson, whom I saw \\
\hline space I & $\begin{array}{l}\text { J: he had seen the woman who lives at } \\
219 \text { Main Street }\end{array}$ \\
\hline
\end{tabular}

In 9, the wording the woman who lives at 219 Main Street is used instead of Mary Wilson. The reason why such substitution is allowed is as follows: (a) space $\mathrm{R}$ as well as space $\mathrm{S}$ holds the notion 'Mary Wilson', and (b) the wording the woman who lives at 219 Main Street used as a representation of the notion 'Mary Wilson' has originated from space $\mathrm{R}$ (the speaker's reality).

Similarly, in 8, we can see the substitution of words. In this case, Len's original belief as cognized by the speaker is as follows:

(10) Len's original belief: 'Lisa has green eyes.'

And the speaker of 8 uses the wording the girl with blue eyes instead of Lisa. The reason why such substitution is allowed in 8 is that (a) space $\mathrm{R}$ as well as space $\mathrm{S}$ holds the notion 'Lisa' and (b) the girl with blue eyes used as a representation of the notion 'Lisa' has originated from space R. Green eyes in 10, on the other hand, cannot be re-expressed in indirect speech by wording like blue eyes because space $\mathrm{R}$ does not hold the notion 'green eyes' as a property of Lisa. Nor can Lisa in 10 be reexpressed in indirect speech by wording like the girl with green eyes because the wording as a representation of the notion 'Lisa' has not originated from space R. (This explains why the speaker cannot say something like Len believes that the girl with green eyes has blue eyes in the context shown in 8.)

Thus the following generalization can be given: the speaker of an indirect speech can represent a notion expressed in the original utterance or thought by using words different from the original ones if and only if (a) space $\mathrm{R}$ also holds the notion and (b) the wording used by the speaker as a representation of the notion has originated from space $R$.

2.6. INDIRECT SPEECH AND DEIXIS. In indirect speech, shifting of deictic features is in many cases natural, because the situation of the utterance by the speaker may differ from that of the utterance by the 
original speaker. A typical example of changes in wording is as follows:

(11) a. Ben's original utterance: 'I arrived here yesterday.'

b. Ben said that he had arrived there the previous day.

The mental construction of the speaker of $11 \mathrm{~b}$ can be represented by the RSI-model as shown in Table 4. The speaker of $11 \mathrm{~b}$ interprets Ben's original utterance $(\mathrm{P})$ from his own standpoint represented by zero-point (I, here, now) in space R; where ' $\mathrm{I}$ ' refers to the speaker, 'here' $\left(\mathrm{p}_{0}\right)$ refers to the place of the utterance, and 'now' $\left(t_{0}\right)$ refers to the time of the utterance. $P$ is given by $B e n$, at the place $p_{1}$ which is distinct from $\mathrm{p}_{0}$, and at the time $t_{1}$ before $t_{0}\left(t_{1}\right.$ and $t_{0}$ belong to different days). In space $I$, therefore, Ben's zero-point is interpreted as (he, there, then), and $J$ ('he had arrived there the previous day') is formed.

Table 4

\begin{tabular}{l|l}
\hline space $\mathrm{R}$ & zero-point: $\left(\mathrm{I}(=\right.$ speaker $)$, here $\left(=\mathrm{p}_{0}\right)$, now $\left.\left(=\mathrm{t}_{0}\right)\right)$ \\
\hline space $\mathrm{S}$ & Ben's zero-point: $\left(\mathrm{I}(=\mathrm{Ben})\right.$, here $\left(=\mathrm{p}_{1}\right)$, now \\
& P: I arrived here yesterday \\
\hline space I & $\begin{array}{l}\text { Ben's zero-point: (he, there, then }) \\
\text { J: he had arrived there the previous day }\end{array}$ \\
\hline
\end{tabular}

We should notice here, however, that the verb forms in the reported clauses are not necessarily backshifted according to the tense forms in the reporting verbs. In 12 , for example, the present form is retained in the indirect speech:

(12) Galileo claimed that the earth moves.

The mental construction of the speaker of 12 can be represented by the RSI-model as shown in Table 5. In space $I$, the speaker interprets $P_{2}$ on the basis of $\mathrm{P}_{1}$ and judges that $\mathrm{P}_{2}$ has current validity. Hence the speaker does not distinguish Galileo's zero-point concerning the time from his own zero-point.

Similarly, if the location of the original speaker's zero-point is not distinguished from that of the speaker's zero-point, the place-reference of the original utterance is not shifted in indirect speech:

(13) a. George's original utterance: 'I will be here again.'

b. George said that he would be here again.

In this case, as Table 6 shows, George's original utterance is given at the place $\mathrm{p}_{0}$. The speaker of $13 \mathrm{~b}$ is also at $\mathrm{p}_{0}$. Thus the original wording for place-reference (here) is retained in space $\mathrm{I}$, and hence retained in $18 \mathrm{~b}$. 
Table 5

\begin{tabular}{c|l}
\hline space $\mathrm{R}$ & $\begin{array}{l}\left.\text { zero-point: (I }(=\text { speaker }) \text {, here }\left(=\mathrm{p}_{0}\right) \text {, now }\left(=\mathrm{t}_{0}\right)\right) \\
\mathrm{P}_{1} \text { : the earth moves }\end{array}$ \\
\hline space $\mathrm{S}$ & $\begin{array}{l}\text { Galileo's zero-point: }\left(\mathrm{I}(=\mathrm{Galileo}) \text {, here }\left(=\mathrm{p}_{1}\right),\right. \\
\left.\text { now }\left(=\mathrm{t}_{1}\right)\right)\end{array}$ \\
\hline space $\mathrm{I}$ & $\begin{array}{l}\text { Galileo's zero-point: (he, the earth moves } \\
\mathrm{J}: \text { the earth moves }\end{array}$ \\
\hline
\end{tabular}

Table 6

\begin{tabular}{|c|c|}
\hline space $\mathrm{R}$ & zero-point: $\left(\mathrm{I}(=\right.$ speaker $)$, here $\left(=\mathrm{p}_{0}\right)$, now $\left.\left(=\mathrm{t}_{0}\right)\right)$ \\
\hline space $\mathrm{S}$ & $\begin{array}{l}\text { George's zero-point: }\left(\mathrm{I}(=\text { George }) \text {, here }\left(=\mathrm{p}_{0}\right) \text {, }\right. \\
\left.\text { now }\left(=\mathrm{t}_{1}\right)\right) \\
\text { P: I will be here again }\end{array}$ \\
\hline space I & $\begin{array}{l}\text { George's zero-point: (he, here, then) } \\
\mathrm{J} \text { : he would be here again }\end{array}$ \\
\hline
\end{tabular}

A basic generalization, therefore, is that deictic features in indirect speech are to be different from those of the original utterance if and only if the original speaker's zero-point in space I differs from the speaker's zero-point (in space R) in person, place, or time.

3. METAPHOR. In this section, I will try to clarify the mental basis of expressions of metaphor in terms of the RSI-model proposed in Section 2. Here, I would like to treat metaphor as a natural reflection of the speaker's cognition. ${ }^{4}$

3.1. Mental spaces as the basis of Metaphor. I will first consider the following metaphorical expression about a person named Ellen:

(14) Ellen is an angel.

(Thomas 1969: 4)

${ }^{4}$ Kawakami 1986 argues that linguistic phenomena such as trope and irony are linguistic projections of the speaker's cognition. The present argument supports his view of the relationship between language and cognition. 
Here, the function of an angel is essentially the same as that of a predicate adjective; it describes a particular characteristic of Ellen. The characteristic may be 'beautiful', 'kind', 'good', or 'merciful', which is the same as what the speaker regards as a characteristic of an angel. What should be noticed here is that not all characteristics of an angel is involved in the meaning of the metaphor. 'Having large wings', for example, which is a physical characteristic of an angel, is not involved in the meaning of 14. What is involved is a nature that appeals to the speaker's emotion. That is, what the speaker expresses is an impression he has got from Ellen, and he expresses it by using his impression of an angel. His thought that the impression he has got from Ellen is identical with his impression of an angel is the mental basis of the metaphorical expression in 14 .

The mental basis of the expression in 14 can be represented by the RSImodel as shown in Table 7. Both the content of space $\mathrm{R}(a)$ and that of space $\mathrm{S}(e)$ are notions which the speaker has extracted from his system of knowledge. The system of knowledge contains his knowledge of various entities obtained through his intellectual and emotional experiences. Let us suppose here that the speaker intends to speak about Ellen's beauty. In this case, the speaker extracts his knowledge of Ellen including his impression that she is beautiful from his system of knowledge and makes it the subject (or theme) of the expression, i.e. the content of space $S$.

In this table, the nature of $e$ is represented by the word beautiful for convenience' sake. However, the meaning of beautiful is abstract: it does not exactly describe the specific beauty of Ellen cognized by the speaker. (The word beautiful can indeed be used for describing various entities which have beauty, but the qualities of their beauty may be different from one another.) It is hard to describe the quality of Ellen's particular beauty specifically in words. It would be no use searching for a word which would correspond in its lexical meaning to the quality of her beauty. The speaker therefore searches his system of knowledge for a

Table 7

\begin{tabular}{l|l}
\hline space $\mathrm{R}$ & $a:$ an angel, beautiful \\
\hline space $\mathrm{S}$ & $e:$ Ellen, beautiful \\
\hline space $\mathrm{I}$ & $\mathrm{J}: e$ has the same nature as $a$ does \\
\hline
\end{tabular}


notion which has the same quality of beauty as Ellen does and extracts the notion of an angel $a$ as the content of space R, namely, the reality relating to the content of space $\mathrm{S}$.

In space I, the speaker interprets $e$ and judges that $e$ has the same nature as $a$ does. That is, in this space he judges that the impression that he has got from Ellen is just the same as his impression of an angel. The judgment represented as $\mathbf{J}$ is reflected in the metaphorical expression in 14.

3.2. The nature Common to the two entities. What we should notice here is that we can cognize metaphorical relationship between two entities even though there is no physical similarity between them. For example:

(15) Thus must I from the smoke into the smother;

From tyrant duke unto a tyrant brother:

-Shakespeare, As You Like It, 1. 2. 299-300.

The mental construction of the speaker of 15 (i.e. Orlando) can be represented by the RSI-model as shown in Table 8. The tyrant duke and Orlando's cruel brother are both human beings; they have no physical characteristic in common with smoke or smother (i.e. suffocating smoke). In Orlando's mind, however, they are similar in that both of them make him suffer a great deal. That is to say, the notions of smoke and smother represented as $s$ and $s t$ respectively in space $\mathrm{R}$ and the notions of the duke and Orlando's brother represented as $d$ and $b$ respectively in space $\mathrm{S}$ do have the same nature. For him, to go from $d$ to $b$ Table 8

\begin{tabular}{c|l}
\hline space $\mathrm{R}$ & $\begin{array}{l}\text { to go from } s \text { to } s t \text { : miserable } \\
s: \text { smoke, which makes me (= Orlando) suffer a } \\
\text { great deal }\end{array}$ \\
& $s t:$ smother, which makes me suffer a great deal \\
\hline space $\mathrm{S}$ & $\begin{array}{l}\text { to go from } d \text { to } b: \text { miserable } \\
d: \text { tyrant duke, who makes me suffer a great deal } \\
b: \text { tyrant brother, who makes me suffer a great deal }\end{array}$ \\
\hline space I & $\begin{array}{l}\mathrm{J}: \text { my anguish caused by the fact that I must go } \\
\text { from } d \text { to } b \text { is identical with the anguish caused } \\
\text { by going from } s \text { to } s t\end{array}$ \\
\hline
\end{tabular}


is therefore as miserable as to go from $s$ to $s t$. In space I, he judges that his anguish caused by the fact that he must go from $d$ to $b$ is identical with the anguish caused by going from $s$ to $s t$.

The following example also includes a metaphor in which the two entities expressed have no physical characteristic in common:

(16) Here feel we but the penalty of Adam, The seasons' difference, as the icy fang And churlish chiding of the winter's wind, Which, when it bites and blows upon my body, Even till I shrink with cold, I smile and say 'This is no flattery: these are counsellors That feelingly persuade me what I am.'

-Shakespeare, As You Like It, 2. 1. 5-11. In this case, the speaker (i.e. Duke) finds similarity between 'the icy fang and churlish chiding of the winter's wind' and 'counsellors' though there is no physical characteristic common to them. The winter's wind bites and blows upon his body even till he shrinks with cold, and it is perceived through his tactile organ. The words of counsellors, on the other hand, are perceived through his auditory organ. The process of perceiving the coldness of the wind is different from that of perceiving counsellors' words. However, the severity of the winter's wind and that of counsellors' words are identical: both of them feelingly persuade him of what he is. As Table 9 shows, Duke judges that $w$ in space $\mathrm{S}$ has the same nature as $c$ in space $\mathbf{R}$ does. The judgment $\mathbf{J}$ is reflected in the metaphorical expression in 16 .

Table 9

\begin{tabular}{c|c}
\hline space $\mathrm{R}$ & $\begin{array}{c}c: \text { counsellors, who feelingly persuade me (= Duke) } \\
\text { what I am }\end{array}$ \\
\hline space $\mathrm{S}$ & $\begin{array}{l}w: \text { the icy fang and churlish chiding of the winter's } \\
\text { wind, which feelingly persuade me what I am }\end{array}$ \\
\hline space $\mathrm{I}$ & $\mathrm{J}: w$ has the same nature as $c$ does \\
\hline
\end{tabular}

From the discussion above, we can reach the conclusion that what is concerned with a metaphorical expression 'A is B' is not a physical characteristic common to the external entities $\mathrm{A}$ and $\mathrm{B}$ but a characteristic common to the notions $a$ and $b$. These notions are elements in mental spaces, which the speaker has got through perceiving and cognizing $\mathrm{A}$ and B. The expression 'A is B' reflects the speaker's judgment that $a$ has 
the same nature as $b$ does.

4. IRONY. In this section, I will consider the mental basis of expressions of irony in terms of the RSI-model.

On the relationship between cognition and expression of irony, Kawakami 1984, 1986 presents a highly convincing idea. As he observes, a linguistic theory of irony should explain why a particular expression is chosen as an ironical expression by the speaker. Nevertheless, linguistic studies on irony in the past did not succeed in explaining it because they concentrated on the form of linguistic expressions and overlooked the relationship between cognition and expression of irony (see Kawakami 1984: 175-88). The main point of Kawakami's theory of irony is as follows:

(17) The expression of an irony is a linguistic projection of speaker's cognition of the irony: speaker's cognition of the contrary disparity between prior beliefs (X) and present ones (un-X) concerning the understanding of given situations.

Kawakami's idea summarized as 17 is of crucial importance in considering the essence of irony. In this section, therefore, I will argue on irony in favor of his theory. The cognitive model used in the present argument, however, is distinct from that used in his theory. Kawakami 1984 proposes a cognitive model which has quater-polar structure (which consists of the poles $\mathrm{R},-\mathrm{R}, \mathrm{F}$, and $-\mathrm{F}$ ). In that model, prior beliefs and present ones concerned with cognition of irony are represented by values in conceptual scales on $\mathrm{X}$-axis and $\mathrm{Y}$-axis respectively, and the cognition of irony is represented by the point $F$ with an abscissa $p$ and an ordinate $-p$ or by the point $-\mathrm{F}$ with an abscissa $-\mathrm{p}$ and an ordinate $\mathrm{p}$. In the RSImodel proposed in the present study, on the other hand, prior beliefs, present ones, and the cognition of irony are represented by the content of three mental spaces: space S, space $R$, and space I respectively.

4.1. Cognition AND EXPRESSION OF IRONY. In this subsection, I will consider the mechanism of cognition and expression of irony.

The first example shown in 18 is from Little Women by L. M. Alcott. Jo, who knows little about culinary affairs, willingly offers to make the dinner, and goes to the kitchen:

(18) Leaving the others to console Beth, she [Jo] departed to the kitchen, which was in a most discouraging state of confusion. Putting on a big apron she fell to work, and got the 
dishes piled up ready for washing, when she discovered that the fire was out. 'Here's a sweet prospect!' muttered Jo, slamming the stove-door open, and poking vigorously among the cinders.

-L. M. Alcott, Little Women, p. 150. The mental construction of Jo (i.e. the speaker of the utterance Here's a sweet prospect!) can be represented by the RSI-model as shown in Table 10. Both the content of space $R$ and that of space $S$ are notions which Jo has extracted from her system of knowledge. Jo's prior expectation about the kitchen $\left(k^{\prime}\right)$ has come to be the content of space $\mathrm{S}$ because Jo intends to speak about her prior expectation by means of the utterance in 18. ${ }^{5}$ That is, $k^{\prime}$ is the subject (or theme) of the ironical expression. Her knowledge of the present state of the kitchen $(k)$, on the other hand, has come to be the content of space $\mathrm{R}$ because it is her reality relating to the content of space S. In space I, Jo interprets $k^{\prime}$ on the basis of $k$ and judges that the state of $k^{\prime}$ is contrary to that of $k$. The judgment $\mathrm{J}$ is to be characterized as cognition of irony, namely, the mental basis of the ironical expression in 18.

Table 10

\begin{tabular}{l|l}
\hline $\begin{array}{l}\text { space R } \\
\text { (Jo's present reality) }\end{array}$ & $\begin{array}{l}k: \text { the kitchen, where it is hard to } \\
\text { work }\end{array}$ \\
\hline $\begin{array}{l}\text { space S } \\
\text { (Jo's prior expectation) }\end{array}$ & $\begin{array}{l}k^{\prime}: \text { the kitchen, where it is easy to } \\
\text { work }\end{array}$ \\
\hline space I & $\begin{array}{l}\mathrm{J}: \text { the state of } k^{\prime} \text { is contrary to that } \\
\text { of } k\end{array}$ \\
\hline
\end{tabular}

The ironical expression in 18 , in which the sense of her utterance is inconsistent with her attitude, reflects her mental construction represented above. The sense of her utterance is appropriate only to the state of the kitchen which is just as she expected. In fact, however, the kitchen is in a most discouraging state of confusion. Her cognition of the reality $(k)$ is reflected in the tone of her voice shown by the word muttered and in her attitude shown in the narrative part, i.e. slamming the stove-door

${ }^{5}$ In other words, the existence of $k^{\prime}$ (Jo's prior expectation) motivates her to express irony. 
open, and poking vigorously among the cinders. Her speech and action ironically show the content of space I, namely, her judgment that the state of $k^{\prime}$ is contrary to that of $k$.

What should be noticed here is that the speaker's present reality is sometimes reflected not only in his attitude or tone of voice but also in his wording itself. For example:

(19) I like thàt. Bob smashes up my car and then expects me to pay for the repairs.

(Quirk et al. 1985: 1463)

The mental construction of the speaker of 19 can be represented by the RSI-model as shown in Table 11. In space I, the speaker interprets his prior expectation about Bob $\left(b^{\prime}\right)$ and judges that the behavior of $b^{\prime}$ is contrary to that of $b$.

Table 11

\begin{tabular}{l|c}
\hline $\begin{array}{l}\text { space R (speaker's } \\
\text { present reality) }\end{array}$ & $\begin{array}{l}b: \text { Bob, who expects me to pay for the } \\
\text { repairs }\end{array}$ \\
\hline $\begin{array}{l}\text { space S (speaker's } \\
\text { prior expectation) }\end{array}$ & $b^{\prime}:$ Bob, who himself pays for the repairs \\
\hline space I & $\begin{array}{l}\mathrm{J}: \text { the behavior of } b^{\prime} \text { is contrary to that } \\
\text { of } b\end{array}$ \\
\hline
\end{tabular}

The judgment formed in space $I$ is reflected in the expression in 19. The expression consists of two parts: I like thàt and Bob smashes up my car and then expects me to pay for the repairs. The former shows the speaker's mental reaction which would rise only when the behavior of Bob was just as the speaker expected. The latter shows the speaker's present reality faithfully. The inconsistency seen in the whole expression is a reflection of $\mathrm{J}$.

Generally, expression of irony can be characterized as inconsistent performance by means of words, tones of voice, attitudes, and so on, which reflects inconsistency cognized in space I, i.e., the speaker's judgment that his prior belief or expectation is contrary to his present reality.

4.2. APPEARANCE AND REALiTy. The etymological sense of the word irony is 'dissimulation' (Gk. eirōneía ignorance purposely affected). Therefore the notion of irony involves two conflicting notions of appearance and reality (see Kawakami 1986: 3). In this subsection, I will consider how these essential notions are concerned with cognition and ex- 
pression of irony.

The following example is from the scene of 'the play within the play' in Shakespeare's Hamlet. Claudius, the king of Denmark, talks with Hamlet in the interval of the play within the play:

(20) King. Have you heard the argument? Is there no offence in 't?

Ham. No, no, they do but jest, poison in jest; no offence i' the world.

King. What do you call the play?

Ham. The Mouse-trap. Marry, how? Tropically. This play is the image of a murder done in Vienna: Gonzago is the duke's name; his wife, Baptista: you shall see anon; 'tis a knavish piece of work: but what o' that? your majesty and we that have free souls, it touches us not: let the galled jade wince, our withers are unwrung.

-Shakespeare, Hamlet, 3. 2. 242-53. (Italics mine.)

Just after their talking, the murder of Gonzago is performed; the king stands up and runs off the moment that he sees it.

The mental construction of the speaker of the italicized part (i.e. Hamlet) can be represented by the RSI-model as shown in Table 12. At the time of the utterance, Hamlet believes that the king (i.e. Claudius) murdered the late king and that the soul of the king is bound by guilt. This belief on the reality of the king belongs to space $\mathrm{R}$ as the notion $k$. Space $\mathrm{S}$ contains $k^{\prime}$, the notion of the king whose soul is free from guilt. Before Hamlet met the ghost of his father, he did not know that Claudius had murdered him and therefore he did not realize that $k^{\prime}$ is the appearance of Claudius. By listening to the ghost of his father, however, he has realized that $k^{\prime}$ is the appearance, not the reality, of Claudius; and he has got the new belief $k$. In space I, he interprets $k^{\prime}$ (the subject of the ironical expression) on the basis of $k$ and judges that the mind of $k^{\prime}$ is contrary to that of $k$.

Table 12

\begin{tabular}{l|c}
\hline $\begin{array}{l}\text { space } \mathrm{R} \\
\text { (reality) }\end{array}$ & $\begin{array}{l}k: \text { the king, the murderer of the late king, } \\
\text { whose soul is bound by guilt }\end{array}$ \\
\hline $\begin{array}{l}\text { space } \mathrm{S} \\
\text { (appearance) }\end{array}$ & $\begin{array}{l}k^{\prime}: \text { the king, not the murderer of the late } \\
\text { king, whose soul is free from guilt }\end{array}$ \\
\hline space I & $\mathrm{J}:$ the mind of $k^{\prime}$ is contrary to that of $k$ \\
\hline
\end{tabular}


On the basis of the judgment formed in space I, the ironical expression in 20 (i.e. the italicized part) is made. The sense of the utterance is in conformity with the appearance of the king. What should be noticed here is that Hamlet expresses bitter irony by combining the sense of the utterance with the content of the play within the play. He clearly shows the way in which the king murdered the late king and pretends to believe that it is but the play and that it does not touch the 'free' soul of the king at all. That is, he expresses the appearance of the king in words italicized in 20 and the reality of the king in the play within the play. The inconsistency seen in the whole expression can be characterized as a reflection of his judgment $\mathbf{J}$ in space $I$.

The king, the hearer of the italicized part, is also conscious that his appearance is contrary to his reality, i.e., that he is on the throne by deceiving the whole country, though he is the murderer of the late king. When the italicized part is uttered, however, he does not notice that Hamlet knows the reality and intends to express irony. It is at the time of the performance of murder in the play within the play when the king notices the intention of Hamlet and realizes that Hamlet knows the reality of the king which is contrary to his appearance. That is reflected in the king's reaction, namely, standing up in the middle of the play and running off.

5. Conclusion. In this paper, I have defined the notion of mental spaces as constructs which the speaker has in his mind at the time of the utterance as the basis of the linguistic expression, and have explored the mental basis of expressions such as indirect speech, metaphor, and irony. In order to clarify the speaker's mental construction, I have proposed a new mental-space model termed the RSI-model, which consists of three mental spaces: space $R$, space $S$, and space $I$. The content of space $R$ is the speaker's mental reality relating to the content of space $S$. The content of space $S$ is what the speaker intends to speak about, namely, the subject of the expression by the speaker. Both the content of space $\mathbf{R}$ and that of space $S$ have been extracted from the speaker's system of knowledge. Space $I$ is a space in which the speaker interprets the content of space $S$ on the basis of the content of space $R$. The judgment formed in space $I$ is reflected in the linguistic expression. Indirect speech is a reflection of the speaker's judgment as the result of interpretation of the original utterance or thought in space $S$ on the basis of the content of space $\mathrm{R}$. Metaphor is a reflection of the speaker's judg- 
ment that the notion in space $\mathrm{S}$ has the same nature as the notion in space $\mathbf{R}$ does. Irony is a reflection of the speaker's judgment that his prior belief or expectation in space $\mathrm{S}$ is contrary to his present reality in space R. These linguistic expressions are all based on space I.

\section{REFERENCES}

FAUCONNIER, Gilles. 1985. Mental spaces: Aspects of meaning construction in natural language. Cambridge, MA: MIT Press.

Frege, Gottlob. 1892. On sense and reference. Readings in semantics, ed. by Farhang Zabeeh, E. D. Klemke, and Arthur Jacobson, 1974, 118-40. Urbana, Chicago, London: University of Illinois Press.

Hasegawa, KInsuKe. 1972. Transformations and semantic interpretation. LI 3. $141-59$.

HIRose, YUKIO. 1986. Referential opacity and the speaker's propositional attitudes. Tokyo: Liber Press.

JACKENDOFF, RAY. 1975. On belief-contexts. LI 6.53-93.

- 1983. Semantics and cognition. Cambridge, MA: MIT Press.

Jespersen, Otto. 1924. The philosophy of grammar. London: George Allen \& Unwin.

KaWakami, SeIsaku. 1984. Bun no imi ni kansuru kisoteki-kenkyu. Osaka daigaku bungakubu kiyo, vol.24.

- 1986. Ninshiki no tōei to shite no gengo: Trope to irony no baai. The rising generation 132.2-6.

Kiparsky, Paul, and Carol Kiparsky. 1970. Fact. Semantics: An interdisciplinary reader in philosophy, linguistics and psychology, ed. by Danny D. Steinberg and Leon A. Jakobovits, 1971, 345-69. Cambridge: Cambridge University Press.

Lakoff, George, and Mark Johnson. 1980. Metaphors we live by. Chicago and London: The University of Chicago Press.

Leech, Geoffrey N. 1983. Principles of pragmatics. London and New York: Longman.

McCAwley, James D. 1970. Where do noun phrases come from? Readings in English transformational grammar, ed. by Roderick A. Jacobs and Peter S. Rosenbaum, 166-83. Waltham, MA: Ginn and Company.

Narita, Yoshimitsu. 1987. Bun no goyōronteki-imi. Nihongogaku 6.7.13-21. Ortony, Andrew. ed. 1979. Metaphor and thought. Cambridge: Cambridge University Press.

Postal, Paul M. 1974. On certain ambiguities. LI 5.367-424.

Quirk, Randolph, Sidney Greendaum, Geoffrey Leech, and Jan Svartvik. 1985. A comprehensive grammar of the English language. London and New York: Longman.

RicharDs, I. A. 1936. The philosophy of rhetoric. New York: Oxford University Press. 
Sperber, Dan, and DeIRDRE WiLson. 1981. Irony and the use-mention distinction. Radical pragmatics, ed. by Peter Cole, 295-318. New York: Academic Press. . 1986. Relevance: Communication and cognition. Cambridge, MA: Harvard University Press.

Thomas, Owen. 1969. Metaphor and related subjects. New York: Random House. Yasui, Minoru. 1978. Gengai no imi. Tokyo: Kenkyusha. 